\title{
Patient satisfaction with perioperative care among patients having orthopedic surgery in a university hospital
}

This article was published in the following Dove Press journal:

Local and Regional Anesthesia

27 July 2010

Number of times this article has been viewed

\author{
Hatem A Jlala' \\ Monique A Caljouw ${ }^{2}$ \\ Nigel M Bedforth' \\ Jonathan G Hardman' \\ 'University Department of Anesthesia, \\ Queens' Medical Center, Nottingham, \\ UK; ${ }^{2}$ Department of Public Health \\ and Primary Care, Leiden University \\ Medical Centre, The Netherlands
}

\begin{abstract}
This survey aimed to validate the English version of the multidimensional Leiden Perioperative Patient Satisfaction questionnaire (LPPSq) and use it to assess patient satisfaction with perioperative care and the influence of type of anesthesia. One hundred patients having orthopedic surgery under regional and general anesthesia verbally consented to participate. Different aspects of satisfaction were assessed (eg, provision of information, and staff-patient relationship). The reliability estimate of the LPPSq (Cronbach's- $\alpha$ ) was good (0.94). Overall, patient satisfaction score was $86.7 \%$, lowest was for information (80.8\%) and highest for staffpatient relationships $(90.3 \%)$. Patients were more satisfied with the provision of information regarding regional anesthesia.
\end{abstract}

Keywords: Leiden Perioperative Patient Satisfaction questionnaire, orthopedic, anesthesia, information

\section{Introduction}

Patient satisfaction and experience of the quality of care is a difficult outcome to measure, mainly because it is a subjective multidimensional concept, based on patient expectations. ${ }^{1}$ The literature abounds with studies that looked at assessing different aspects of patient satisfaction using different rating scales. ${ }^{2,3}$ Those assessment tools (questionnaires) were mainly unidimensional (eg, visual analog scale); and high levels of satisfactions were usually expressed by patients. ${ }^{2,4}$

Development and use of a self-reported multidimensional questionnaire, combining several dimensions have been shown to improve the sensitivity of patient satisfaction assessment tools. ${ }^{2}$ Compared to unidimensional questionnaires, these tools, if properly constructed, produce better quality of data, characterized by more variability and greater validity and reliability in measuring the level of patient satisfaction. ${ }^{5}$

The aim of the present survey was to validate the English version of the multidimensional Leiden Perioperative Patient Satisfaction questionnaire (LPPSq) ${ }^{5}$ among orthopedic surgery patients, assess the level of patient satisfaction with perioperative care, and the influence of type of anesthesia on patient satisfaction.

\section{Methods}

The questionnaire was reviewed by our local research ethics committee and informed consent was deemed unnecessary, although all the approached patients were informed about the aims and nature of the survey. Patients were also informed that their participation was voluntary and that they could withdraw at any time. 


\section{Design}

The English adaptation of the LPPSq was generated by one bilingual researcher translating the Dutch version of the questionnaire into English language. This was then compared to the published translated version from the original author; and a consensus reached between the two translated versions.

The LPPSq was used to assess and measure different aspects of patient satisfaction with perioperative care such as information provision, discomfort and needs, fear and concern, staff-patient relationship, staff professional competence, and service quality.

The English translated questionnaire was extended by adding questions relating to common side-effects of anesthesia (eg, headache, nausea), and the level of information provided about anesthesia. In total, the questionnaire comprised 39 questions, the final draft of which is shown in Appendix A.

\section{Dimensions of the LPPSq} Information provision

Specific questions about the explanation and amount of information provided to patients regarding anesthesia, surgery, and their stay in the operating theatre. This dimension was extended from the original questionnaire by adding questions about anesthesia.

\section{Discomfort and needs}

Investigating whether adverse outcomes of the anesthesia (eg, postoperative pain, vomiting) influenced patient satisfaction. This dimension was extended from the original questionnaire by adding common side-effects of anesthesia (headache, nausea).

\section{Fear and concern}

Regarding the degree of fear and concern among patients in respect to some situations, such as seeing the operating room, or pain level due to administering anesthetics.

\section{Staff-patient relationship}

The relationship between patients and the hospital staff, amount of caring shown toward patients, and the magnitude of patient expectations of the attitude and behavior of the staff toward them (eg, respecting patient privacy, polite attitude). We wanted to assess if the high satisfaction level is determined by improving the relationship between patients and staff.

\section{Professional competence}

The competency and professionalism of the operating theatre staff as perceived by patients, whether staff were attentive to patient needs, and act according to their needs.

\section{Service}

Three questions asked about patient's perception of the waiting time before and after surgery, and if patients were operated on the agreed date and time.

\section{Sample}

One hundred patients were included in the survey, English speaking, more than 18 years old, and scheduled for orthopedic surgery under regional anesthesia (RA) or general anesthesia (GA), between February and April 2009.

All patients were residents of the orthopedic department in Queens' Medical Centre, Nottingham (UK), and able to give competent verbal consent to participate in the survey.

The type of surgery was either upper limb surgery (eg, hand surgery) or lower limb surgery (eg, arthroscopy).

Exclusion criteria were refusal, inability to complete the questionnaire, difficulties in reading or writing English, mixed RA and GA, or conversion of RA to GA.

Demographic data, including patient age, gender, premedication, type of surgery and anesthesia, and history of previous surgery were gathered from the patients and are summarized in Table 1.

\section{Administering the questionnaire}

Patients who fitted in the inclusion criteria were selected and approached on the morning of surgery or a day before for in-patients. The selection process did not involve randomization. The end-point of the survey was collecting 100 questionnaires of equal number of RA and GA.

The purpose of this survey was to assess patient satisfaction with perioperative care (ie, relating to information provision, fears, unwanted adverse effects, staff-patient interaction) using a satisfaction questionnaire. Following explanation of the aims and content of the survey to the participants, verbal consent was obtained from those willing to participate. Questionnaires were then provided and the participants were instructed to read the questionnaire carefully, answer it after the completion of their surgery, and return their completed questionnaire to a survey returns box provided in the department within 3 days of surgery.

Table I Baseline characteristics

\begin{tabular}{ll}
\hline Age (median years (range)) & $70($ I8-80) \\
Gender (F : M) & $57: 43$ \\
Premedication (Yes : No : Not sure) & $31: 36: 33$ \\
Type of anesthesia (GA : RA) & $50: 50$ \\
History of surgery (Yes : No) & $92: 7$ \\
Type of surgery (Upper limb : Lower limb) & $24: 72$ \\
Number of previous operations $(1: 2-3:>3)$ & $29: 35: 29$ \\
\hline
\end{tabular}


We piloted the questionnaire with 50 patients and there were no reported problems related to the reading, understanding, or layout. The response rate for all questions was $>90 \%$, and analysis of this pilot data showed good validity and reliability of the responses. Hence, we decided to use the questionnaire for the survey without further modification.

\section{Statistics}

Statistical analysis (validity, reliability, and factor analysis) was used to validate the questionnaire.

Spearman rank correlation was used to account for the correlation between items scores and their dimension score (inter-item correlation), and between item scores of a given dimension with the other dimensions scores (item discriminant validity).

Chi-squared test was employed to compare the differences in the frequency of side-effects, age, gender, and RA vs GA. A $P$ value of $\leq 0.05$ ( $95 \%$ confidence interval) was set as significant for statistical analysis.

The Mann-Whitney test was used to analyze the influencing characteristics on satisfaction domains and descriptive statistics were used to present patient's mean satisfaction scores (range: $0=$ worst satisfaction; $100=$ perfect satisfaction).

Statistical analysis was performed using the statistics package SPSS (v. 16.0; SPSS Inc, Chicago, USA).

\section{Results \\ Baseline characteristics}

157 patients were approached and 100 patients (74\%) returned a completed questionnaire. Of those, 50 had GA, and 50 had RA. All respondents had orthopedic surgery, either upper limb $(25 \%)$ or lower limb $(75 \%)$. The median age of respondents was 70 years, and the gender proportion was quite even ( $57 \%$ female, $43 \%$ male). Further baseline details are shown in Table 1.

\section{Reliability and validity}

The reliability estimates (Cronbach's- $\alpha$ ) for the scale dimensions and the total English LPPSq (range; 0.65-0.98) were 0.94 . The correlation between item scores and their dimension (inter-item correlation) was considerable, ranging from 0.56 to 0.89 . The reliability of the dimension discomfort and needs was low (Cronbach's- $\alpha=0.21$ ). The internal consistency for the items of all dimensions (item discriminant validity) was either low or not computable (range; 0.01-0.37), indicating a weak correlation between the scores of items of each dimension with other dimensions (Table 2).

\section{Patient satisfaction}

The overall mean patient satisfaction score was $86.7 \%$; the lowest was for information (80.8\%) and highest for staffpatient relationship (90.3\%). Age, gender, type of surgery or anesthesia did not influence overall patient satisfaction scores.

Mean satisfaction scores for RA were similar to that for GA ( $85.8 \%$ vs $88.4 \%$, respectively). However, patients were more satisfied with the amount and explanation of information regarding RA compared to GA ( $91 \%$ vs $77 \%, P=0.02)$. Men and women were similarly satisfied with the quality of care (mean satisfaction score of $87 \%$ vs $87.2 \%$ ). Men generally reported more side-effects and complaints than women, although this has only reached significance with hunger after the operation $($ male $=56 \%$, female $=25 \%, P=0.001$ ).

Among undesirable anesthesia complaints, headache was experienced by $46 \%$ vs $12 \%(P<0.01)$ of patients who had RA compared with GA. Postoperative pain and thirst were frequently mentioned, in both GA and RA groups, with a median score of 3 (severity scoring range; from 1 to 5 ); other postoperative sideeffects (eg, back pain, headache, nausea, cold, and hunger) were less frequently reported with a median score of 1 (Table 3).

Patients were highly satisfied with the way staff dealt with their enquiries and complaints (88.5\%), and they reported a high staff professional competence $(76 \%)$. Patients having

Table 2 Reliability estimates for the scale dimensions and the total LPPSq

\begin{tabular}{|c|c|c|c|c|c|c|c|}
\hline Dimension & $\begin{array}{l}\text { Number of } \\
\text { items within } \\
\text { dimension }\end{array}$ & $\begin{array}{l}\text { Cronbach's- } \alpha \\
\text { coefficient }\end{array}$ & $\begin{array}{l}\text { Mean } \\
\text { dimension } \\
\text { score (SD) }\end{array}$ & $\begin{array}{l}\text { Maximum } \\
\text { possible } \\
\text { dimension score }\end{array}$ & $\begin{array}{l}\text { Satisfaction } \\
(\%)\end{array}$ & $\begin{array}{l}\text { Inter-item } \\
\text { correlation } \\
\text { (IIC) }\end{array}$ & $\begin{array}{l}\text { Item-discriminant } \\
\text { validity (IDV) }\end{array}$ \\
\hline Information & 6 & 0.95 & $24.3(5.83)$ & 30 & 80.8 & $0.77-0.88^{\mathrm{a}}$ & $0.06-0.37$ \\
\hline Fear and & 4 & 0.65 & $16.8(3.15)$ & 20 & 84.2 & $0.56-0.74^{\mathrm{a}}$ & $0.01-0.26$ \\
\hline \multicolumn{8}{|l|}{ Concern } \\
\hline $\begin{array}{l}\text { Staff-patient } \\
\text { relationship }\end{array}$ & 14 & 0.98 & $63.2(10.7)$ & 70 & 90.3 & $0.70-0.89^{a}$ & $0.01-0.36$ \\
\hline LPPSq (English) & 24 & 0.94 & I04.I (15) & 120 & 86.7 & $\mathrm{~b}$ & $\mathrm{~b}$ \\
\hline
\end{tabular}

Notes: ${ }^{a} P<0.0$ I; ${ }^{b}$ not computable. 
Table 3 Prevalence of undesirable anesthesia outcomes, prevalence and difference in the frequency of these outcomes between both types of anesthesia

\begin{tabular}{|c|c|c|c|c|c|c|c|}
\hline \multirow{2}{*}{$\begin{array}{l}\text { Discomfort } \\
\text { and needs }\end{array}$} & \multirow[t]{2}{*}{$\mathbf{N}$} & \multirow{2}{*}{$\begin{array}{l}\text { Prevalence A (little } \\
\text { bit/to extremely) }\end{array}$} & \multirow{2}{*}{$\begin{array}{l}\text { Prevalence B Quite a } \\
\text { bit/to extremely }\end{array}$} & \multirow{2}{*}{$\begin{array}{l}\text { Severity Median } \\
\text { (range) }\end{array}$} & \multicolumn{3}{|c|}{ Type of anesthesia } \\
\hline & & & & & $\overline{\text { GA }}$ & RA & $\mathbf{p}^{\mathbf{a}}$ \\
\hline Post-op pain & 98 & 82.7 & 34.7 & $3.0(I-5)$ & 81.2 & 84.0 & 0.72 \\
\hline Sore throat & 96 & 50.0 & 15.7 & I.5 (I-5) & 68.8 & 1.0 & $<0.01 *$ \\
\hline Back pain & 96 & 27.1 & 9.4 & $\mathrm{I} .0(\mathrm{I}-5)$ & 34.9 & 20.0 & 0.08 \\
\hline Headache & 100 & 29.0 & 8.0 & I.0 (I-5) & 46.0 & 12.0 & $<0.01 *$ \\
\hline Nausea & 97 & 38.3 & 20.2 & $1.0(I-5)$ & 39.1 & 37.5 & 0.87 \\
\hline Cold & 96 & 27.1 & 12.5 & $1.0(I-5)$ & 26.1 & 28.0 & 0.83 \\
\hline Hunger & 98 & 37.8 & 15.3 & I.0 (I-5) & 37.5 & 38.0 & 0.96 \\
\hline Thirst & 96 & 74.5 & 34.0 & $3.0(I-5)$ & 72.7 & 76.0 & 0.72 \\
\hline
\end{tabular}

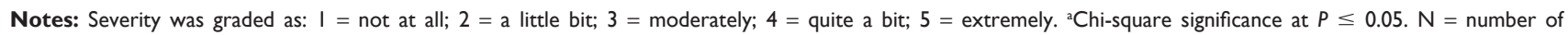
respondents.

RA were satisfied more than those having GA regarding waiting time from leaving recovery room to arrive at the ward $(96 \%$ vs $80 \%, P=0.01)$.

Fear and concern about pain due to surgery was reported by 68 patients compared to only 39 fearing pain due to anesthesia $(P=0.03)$ (Figure 1). Only the fear and concern dimension was influenced by age, type of anesthesia, history of surgery, and amount of discomfort complaints (Table 4). Information and staff-patient relationship domains were significantly correlated $\left(r^{2}=0.6 ; P=0.03\right)$.

\section{Discussion}

In this survey, we have used the English adaptation of the LPPSq to investigate orthopedic patients' perception of different aspects of perioperative care, in particular, the amount and quality of information, fears and concerns, staff-patient relationship, and some common undesirable adverse effects of anesthetics.

The reliability estimates for the LPPSq English version were very good. However, the reliability of the dimension discomfort and needs (undesirable effects of anesthesia) was low; showing poor homogeneity of this dimension with other dimensions. There was also a weak correlation between overall mean patient satisfaction score and the items in this dimension; therefore we did not include this dimension in the construction of the 24-item LPPSq; which may have improved the reliability of the questionnaire. Although it is important to observe and manage concerns of anesthesia and/ or surgery side-effects; they may not be reliable measures to assess patient satisfaction.

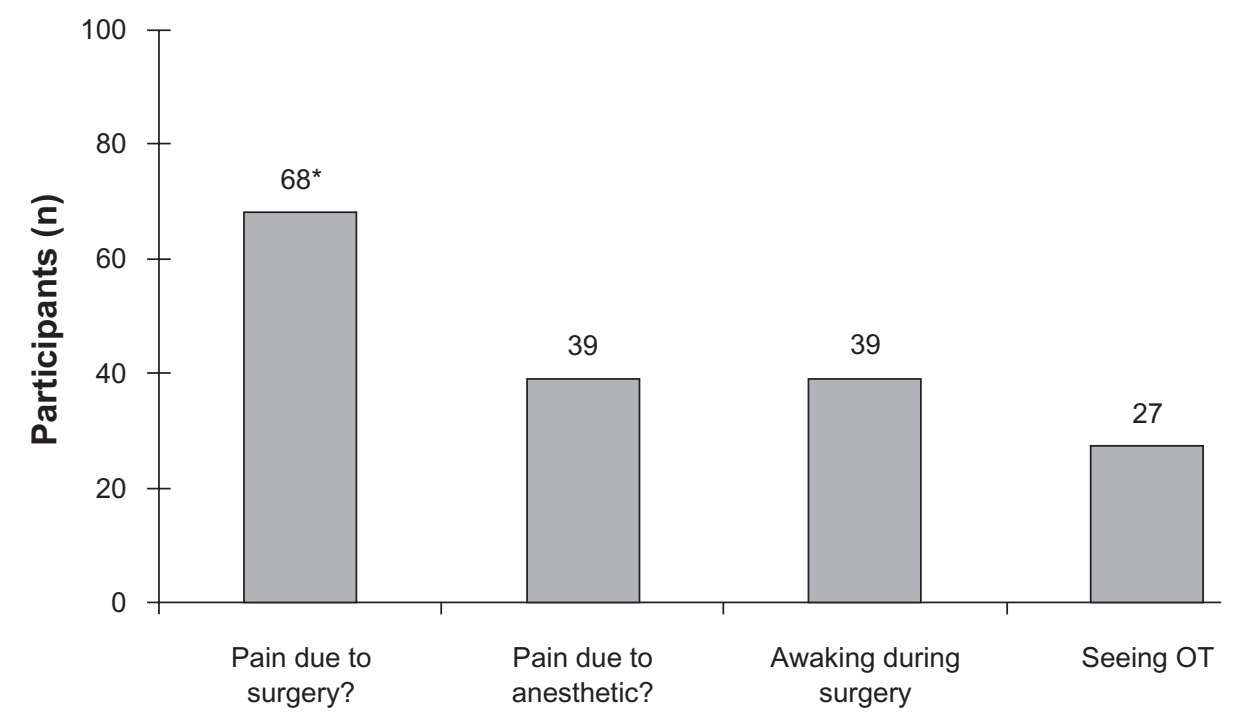

Figure I Fear and concerns about different aspects of perioperative care.

Note: ${ }^{*} P<0.05$.

Abbreviation: OT, operating theatre. 
Table 4 Influencing characteristics on satisfaction domains

\begin{tabular}{lllll}
\hline & Information & $\begin{array}{l}\text { Fear and } \\
\text { concern }\end{array}$ & $\begin{array}{l}\text { Staff-patient } \\
\text { relationship }\end{array}$ & $\begin{array}{l}\text { English } \\
\text { LPPSq }\end{array}$ \\
\hline Age $^{\mathrm{a}}$ & 0 & + & 0 & 0 \\
Gender & 0 & 0 & 0 & 0 \\
$\begin{array}{l}\text { Type of } \\
\text { anesthesia }\end{array}$ & 0 & + & 0 & 0 \\
$\begin{array}{l}\text { History of } \\
\text { surgery }\end{array}$ & 0 & + & 0 & 0 \\
$\begin{array}{l}\text { Amount of } \\
\text { discomfort }\end{array}$ & 0 & + & 0 & 0 \\
complaints & & & & \\
\hline
\end{tabular}

Notes: Correlation with Mann-Whitney test: $0=$ no difference; $P<0.05$; ${ }^{2} \mathrm{Age}$ $\leq 50$ or $>50$ years; ${ }^{\mathrm{A} A m o u n t}$ of complaints $\leq 4$ or $>4$.

Recognizing the importance of involving patients in the construction of the questionnaire, ${ }^{6}$ we piloted this questionnaire with 50 patients to evaluate the applicability and understanding of the different dimensions in the questionnaire. Although we added some items to the original questionnaire; 5 this did not affect the ability of the questionnaire to adequately measure patient satisfaction. In fact, adding some items related to the anesthetics has improved correlation between item scores and their dimension (compared to the original LPPSq).

As expected, overall patient satisfaction scores were high for information and staff-patient relationship. ${ }^{7}$ Amount and quality of information and staff-patient relationship were found to significantly correlate with patient satisfaction. These findings were similar to the original LPPSq. ${ }^{5}$ Both aspects are of more importance than the absence of undesirable outcomes of anesthesia (eg, postoperative pain, nausea, thirst). This shows the importance of provision of information and patient interaction with staff to determine patient satisfaction with care. ${ }^{8}$

Type of anesthesia did not affect patient overall satisfaction scores (ie, patients were similarly satisfied with the care, regardless which anesthetic procedure they had). However, it seems that anesthesiologists tend to disclose "adequate" amounts and quality of information (as perceived by patients) about RA techniques; which resulted in a higher satisfaction. ${ }^{6}$ This may indicate a more standardized explanation of RA techniques.

Nearly $35 \%$ of patients had experienced severe pain after surgery, of whom $18 \%$ had extreme pain. While not identical because of different specialties, this finding was comparable with previously found observed severe postoperative pain (29\%). ${ }^{5}$

Higher satisfaction scores were reported previously by older patients. ${ }^{5,9}$ We were not able to demonstrate this correlation, possibly due to the imbalance in the demographic distribution, as only $20 \%$ of patients were aged less than 50 years.
The majority of the surveyed patients had their operations on the agreed date, and most of them were satisfied with the time spent waiting to be taken to the theatre. Type of anesthesia did not seem to influence their satisfaction in this respect. However, after the operation, patients having surgery under RA spent less time in the recovery room than patients having GA, and this was reflected in the higher satisfaction scores of RA patients. This finding is unsurprising, as patients who have had GA usually require a longer period of observation and support before discharge back to the orthopedic ward.

Patient satisfaction is a subjective and complex concept involving physical, emotional, mental, social, and cultural factors. ${ }^{9}$ It is determined by the quality of the provided care and the expectations of that care. It is assumed that patient experiences or expectations contributed more to higher satisfaction scores than technical aspects of the operation or type of anesthesia. The small differences in satisfaction scores between RA and GA could probably be explained by the underlying concepts of patient satisfaction.

We acknowledge that the English translation of the LPPSq did not utilize the ideal translation process compared to the "translation-back translation" method, or "revision committee and pre-testing". ${ }^{10}$ However, because of the simplicity of all questions in the original questionnaire, we think that our translation approach should satisfy the minimal requirement of these translation processes, and provide the questionnaire with adequate psychometric quality.

\section{Conclusions}

A questionnaire for assessment of patient satisfaction should consist of multiple domains including information provision and communication between patients and medical staff.

We demonstrated good reliability and internal consistency of the LPPS questionnaire (English version). This suggests good construction of the set of questions used. Patient satisfaction with perioperative care in our institution was generally high and the rate of severe, undesirable anesthetic effects was generally low.

There was no difference in overall satisfaction scores between patients having regional or general anesthesia; however, patients were more satisfied with the provision of information before undergoing regional anesthesia.

\section{Disclosure}

The authors report no conflicts of interest in this work.

\section{References}

1. Whitty PM, Shaw IH, Goodwin DR. Patient satisfaction with general anesthesia: too difficult to measure? Anesthesia. 1996;51:327-332. 
2. Wu CL, Naqibuddin M, Fleisher LA. Measurement of patient satisfaction as an outcome of regional anesthesia and analgesia: A systematic review. Reg Anesth Pain Med. 2001;26:196-208.

3. Luber MJ, Greengrass R, Vail TP. Patient satisfaction and effectiveness of lumbar plexus and sciatic nerve block for total knee arthroplasty. J Arthroplasty. 2001;16:17-21.

4. Fung D, Cohen MM. Measuring patient satisfaction with anesthesia care: a review of current methodology. Anesth Analg. 1998;87: 1089-1098.

5. Caljouw MAA, van Beuzekom M, Boer F. Patient's satisfaction with perioperative care: development, validation, and application of a questionnaire. Br J Anesth. 2008;100:637-644.

6. Durieux P, Bissery A, Dubois S, et al. Comparison of health care professionals' self-assessments of standards of care and patients' opinions on the care they received in hospital: observational study. Qual Saf Health Care. 2004;13:198-202
7. Salomon L, Gasquet I, Durieux P, Ravaud P. Taking into account patients' expectations in the improvement of quality of health care: results of a survey of 500 hospitalized patients. Rev Epidemiol Sante Publique. 1998;46:427-429.

8. Krupat E, Hsu J, Irish J, et al. Matching patients and practitioners based on beliefs about care: results of a randomized controlled trial. Am J Manag Care. 2004;10:814-822.

9. Auquier P, Pernoud N, Bruder N, et al. Development and validation of a perioperative satisfaction questionnaire. Anesthesiology. 2005;102: 1116-1123.

10. Perneger TV, Leplège A, Etter J, Rougemont A. Validation of a Frenchlanguage version of the MOS 36-Item Short Form Health Survey in young healthy adults. J Clin Epidemiol. 1995;48:1051-1060. 


\section{Appendix A: Extended, English adaptation of the LPPSq Patient satisfaction with perioperative care}

1. Information provision (Please rate your satisfaction) (completely dissatisfied, dissatisfied, not sure, satisfied, completely satisfied)

- The explanation about anesthesia

- The amount of information about anesthesia

- The explanation about the operation?

- The amount of information about the operation?

- The explanation about your stay at the operating theatre

- The amount of information about your stay in the operating theatre?

2. Discomfort and needs (To what degree after the operation did you feel afraid of....)

(not at all, a little bit, moderately, quite a bit)

- Pain (at the site of the operation)?

- Sore throat?

- Back pain?

- Nausea?

- Vomiting?

- Cold?

- Hunger?

- Thirst?

- Headache?

3. Fear and concern (To what degree after the operation did you feel afraid of....)

(not at all, a little bit, moderately, quite a bit)

- Awaking during the operation?

- Seeing the operating room?

- Pain due to surgery?

- Pain due to anesthetic?
4. Professional competence (Please rate your satisfaction with....)

- Were the staff attentive to your needs (yes or no)?

- Did they act according to your needs (yes or no)?

- Did they consult another health professional (yes or no)?

5. Patient-staff relationship (Please rate your satisfaction) (completely dissatisfied, dissatisfied, not sure, satisfied, completely satisfied)

- Did the theatre staff take into account your privacy?

- Did you have confidence in the theatre staff?

- Had the theatre staff an open attitude?

- Were the theatre staff respectful?

- Did the theatre staff show understanding for your situation

- Were the theatre staff polite?

- Did you find the theatre staff professional?

- Did the theatre staff pay attention to your questions?

- Did the theatre staff pay attention to complaints like pain and nausea?

- Did the theatre staff take into account your personnel preferences?

- Did you find the theatre staff knowledgeable?

- Did the theatre staff pay attention to you as an individual?

- Were you treated kindly by the theatre staff?

- Did you experience professional competence?

6. Service (Please rate your satisfaction with....)

- The waiting time between leaving the ward and having your operation (too long, long, just right, short)

- The waiting time spent in the recovery room and getting back to the ward (too long, long, just right, short).

- Were you operated on the agreed date and time (yes or no)?

\section{Publish your work in this journal}

Local and Regional Anesthesia is an international, peer-reviewed, open access journal publishing on the development, pharmacology, delivery and targeting and clinical use of local and regional anesthetics and analgesics. The journal welcomes submitted papers covering original research, basic science, clinical studies, reviews \& evaluations,

\section{Dovepress}

guidelines, expert opinion and commentary, case reports and extended reports. The manuscript management system is completely online and includes a very quick and fair peer-review system, which is all easy to use. Visit http://www.dovepress.com/testimonials.php to read real quotes from published authors. 